\title{
MARKET SEGMENTATION IS THE KEY TO SUSTAINABLE OPERATION OF B\&B
}

\author{
Li Zhang ${ }^{1}$
}

\begin{abstract}
The Chinese B\&B industry started in 2011, the Mogan Mountain B\&B became the banner of the domestic industry in 2015. Then the entire B\&B industry is imitated and appeared serious homogeneity problems, which forced the manager to look for their own competitive advantage. The objective of the article is through the market segmentation to identifying target customer groups, and combine the orientation of the B\&B with the customer demand. Set up a multi-directional marketing scheme according to the characteristics of the target customer and the behavior of consumption. This article uses the quantitative research method to collect the information. The research shows that the main target customer of $\mathrm{B} \& \mathrm{~B}$ is divided into two categories: 1 tourism vacationers; 2 , weekend vacationers. In conclusion, according to the report on 《Market Prospect and Investment Analysis of B\&B Industry》, the growth rate is 12000/year. By 2017, the B\&B's number is 53852 in China. With the expansion of the $\mathrm{B} \& \mathrm{~B}$ market, which enforces the $\mathrm{B} \& \mathrm{~B}$ industry facing a reshuffle. Therefore, the owners of the $B \& B$ should find the way to sustainable management through the market segmentation.
\end{abstract}

Key words: Bed\&Breakfast industry, market segmentation, target customer, Mogan mountain

\section{INTRODUCTION}

As the "shared economy" heats up everyday, the "shared accommodation", a new industry in recent years into the development of the "fast forward key" state. A large number of people tend to stay close to life, with strong local characteristics of residential houses as an overnight destination when their traveling. Residential accommodation as an important part of Non-standard accommodation, not only enriches the form and content of "living" in the six elements of tourism but also satisfies the increasingly individualized demand for tourism consumption and the need for a primordial state of life (Zeng\&Jiang,2018). Chinese B\&B industry market started in 2011, and in 2015 Mogan Mountain became the banner of the housing industry. More than 80 boutique homes generated 350 million yuan in economic income. In a survey of travel situational preferences from Tujia, 53.1 percent of people wanted to experience local characteristics, folklore and culture when the traveling. This with the personalized and local experience provided by residential matching is pretty high. By the first half of 2018, Tujia has become Chinese largest residential entrance , the entire housing inventory of the other eight platforms. According to the Prospecting Industry Research Institute $<$ Forecast of Market Prospect of B\&B accommodation Industry and Investment

\footnotetext{
${ }^{1}$ Urban Vocational College of Sichuan, 13682015902@163.com,
} 
Analysis report> statistical conclusion, by the end of 2016, there were 53852 B\&Bs all over the country. In 2014 and 2015, the number of B\&B in China is 30231 and 42658. Predict by 2020 , the B\&B market is expected to reach 30-billion-yuan scale. The fast housing growth, surplus new landlords to join, resulting in the overall quality of residential services decline, product imitation phenomenon is serious, the irrational consequences of investment are gradually coming to light. Luo Tao, chief product officer of Tujia's CPO, shared the data that shows a Tujia's online B\&B transactions grew by $180 \%$ in 2017 compared with 2016. The first quarter of 2018 showed a rapid growth of $176 \%$ compared with the first quarter of 2017. At the same time, nearly 1000 merchants join Tujia every day, more than $90 \%$ are the individual operator. In this context, there is a vacancy phenomenon, and some areas even oversupply. Therefore, in order to have a place in the competitive incentive market, it is necessary to re-segment the $\mathrm{B} \& \mathrm{~B}$ market.

Marketing Segmentation is a procession of identifies where is the target market and who is the target customer. It means that a guest-oriented dividing the market into different groups and customers who have similarity needs and interests. (Lazer, Layton, 2000). Geographic and demographic factor are two major Segmentations in hospitality marketing. Firstly, geographic segmentation calls for dividing the market into various geographic areas. Such as nations, states, regions, counties, cities, density, climate, food and culture. Secondly, demographic segmentation is another way in market segmentation. Kotle\&Bowen\&Makens (2014) layout that demographic segmentation is the study of population characteristics, which is consists of separating the marketing into many groups based on demographic different. Such as age, life cycle, gender, income, family size and structure, education, religion, ace and nationality. Under the background of combing the related situation and present situation of the B\&B industry, division of the B\&B market in terms of demographics. The target market is divided into six stages by using the family life cycle standard through the reliable information collected in combination with the current situation in China. They are student stage, single stage, honeymoon stage, former parent stage, middle parent stage, post-parent stage ( Wells \&Gruber, 1966).

Through the family life cycle subdivide the tourism market of the rural boutique houses, help the operators to carry out the market orientation more accurately according to their own resources and advantages. According to the different motivations of different stages of the family life cycle, which can design high-quality B\&B products that meet different needs. In order to find their own target customer groups, business direction and the ability to continue to operate. 
Table 1: The Development trend and present situation of B\&B in China

\begin{tabular}{|l|l|l|l|}
\hline Developmental Stage & The embryonic stage of the 1990s & Early 20th century development stage & Expansion and upgrading after 2010 \\
\hline The key words & Rural individual farm family & Brand development, regional expansion, pattern replication & $\begin{array}{l}\text { Countryside Transformation, Cluster Development f } \\
\text { orms Residential Resort area }\end{array}$ \\
\hline Main functions & Food and sleeping & $\begin{array}{l}\text { Focus on site selection, rely on the advantages of scenic areas, } \\
\text { such as: cultural ancient towns, natural landscape scenic spots } \\
\text { and so on }\end{array}$ & $\begin{array}{l}\text { Become one of the core attraction of scenic spots, } \\
\text { formed }\end{array}$ \\
\hline The level of B\&B & Low grade, incomplete facilities & Upgrade, complete equipment & Boutique,high level, perfect facilities \\
\hline B\&B theme & No theme & $\begin{array}{l}\text { Personalization highlights, theme style and Service concept } \\
\text { are connected }\end{array}$ & $\begin{array}{l}\text { Pay attention to the humanities and integrate into the local } \\
\text { culture, but the homogenization problem also appears c } \\
\text { onstantly }\end{array}$ \\
\hline B\&B services & Villager spontaneous enthusiasm & $\begin{array}{l}\text { The hostundefineds interesting experience, individualized and } \\
\text { characteristic service }\end{array}$ & $\begin{array}{l}\text { Adapting to the local culture to increase the sense of } \\
\text { experience }\end{array}$ \\
\hline Major participants in investment & Villager's spontaneous management & $\begin{array}{l}\text { Individual villagers, collectives of villages and towns, operators Government, hotel group, tourism brand, real estate } \\
\text { and investors outside other villages }\end{array}$ \\
\hline cross-border integration, social capital, crowdfunding, etc.
\end{tabular}

From the above table (Table 1), we can see that the present situation and trend of B\&B have changed from the supplementary option of hotel accommodation to the tourist characteristic attracting destination, and its own size and investment body have shifted from self-employed to supported by group capital. The main function from single to multiple experiences, themes and services reflect the trend of upgrading.

Table2: Ration of male and female\& Number of years of B\&B operators\& Operation mode

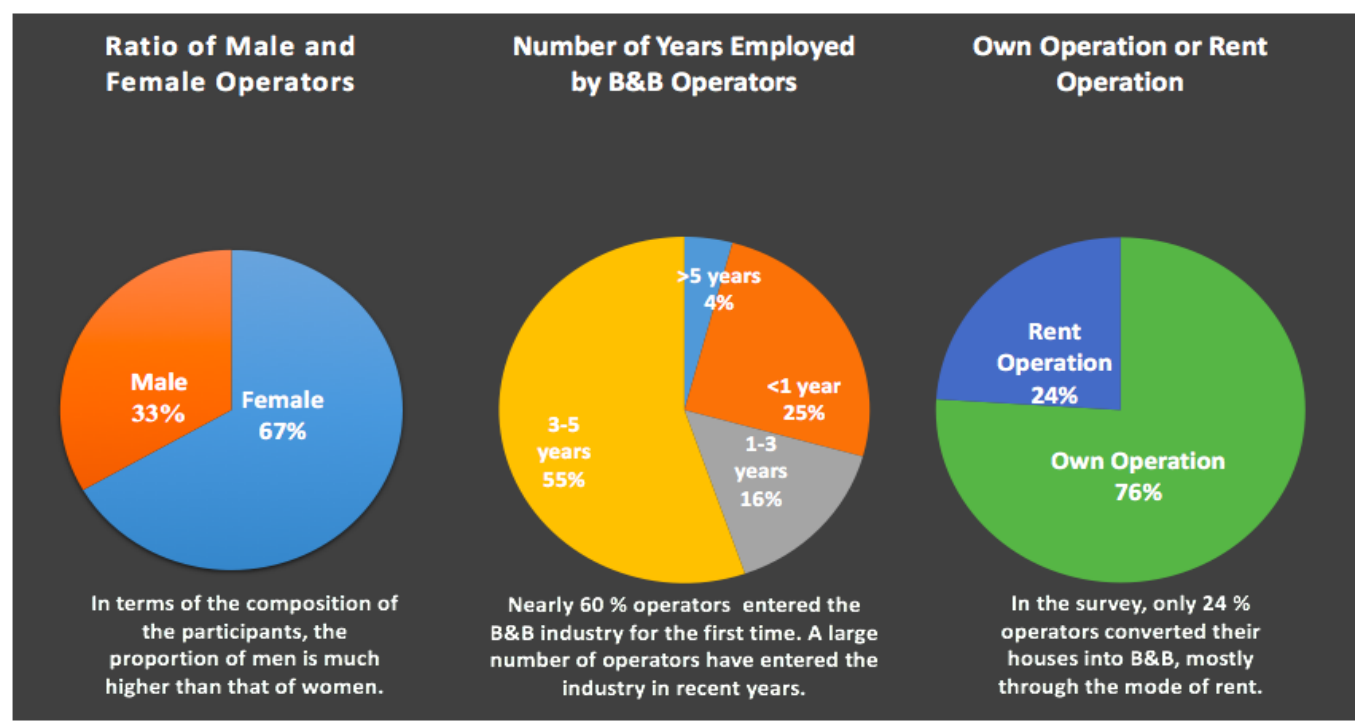

Table 3: B\&B operating income\& B\&B decoration style 


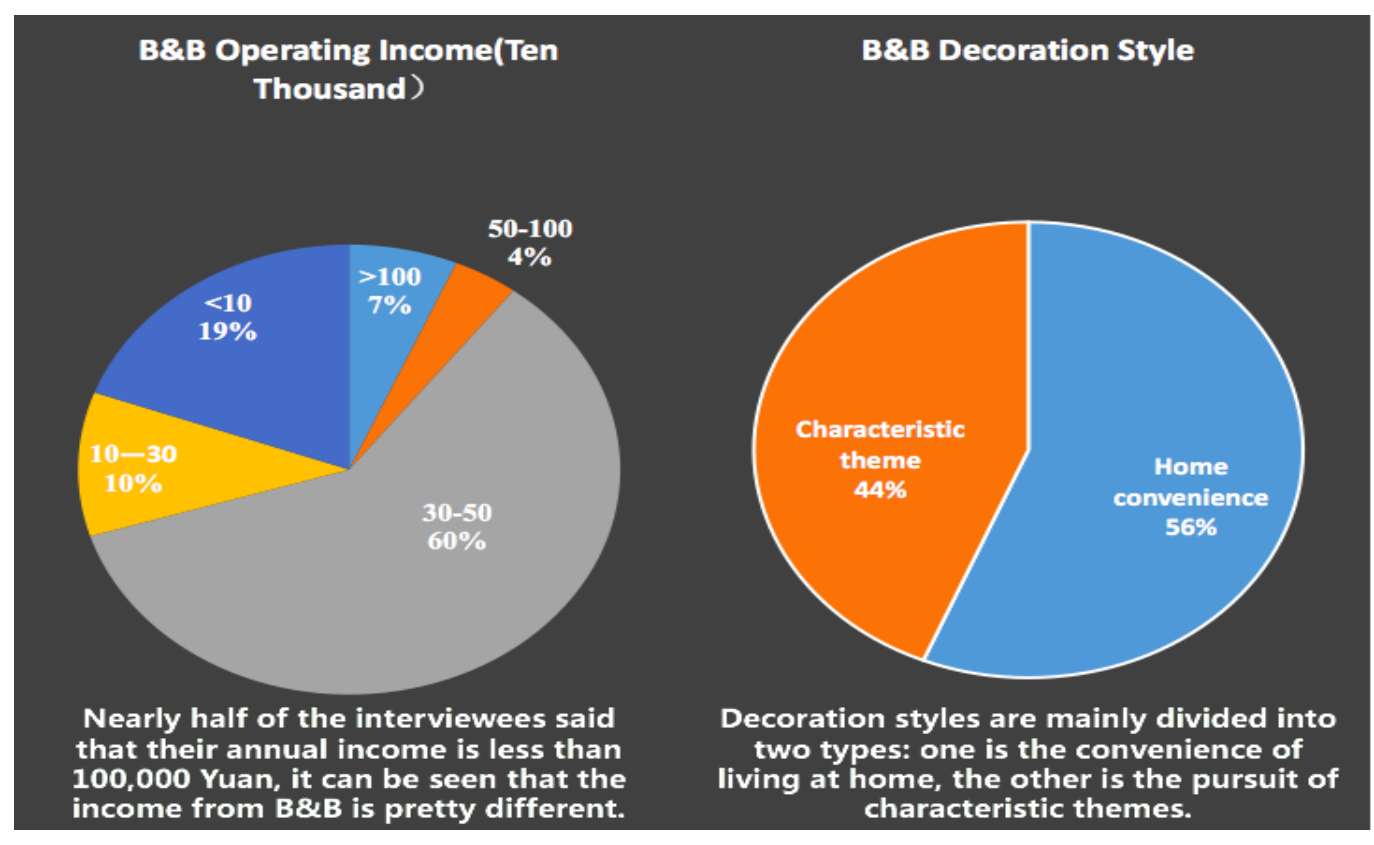

According to the survey data (Table2\&Table 3), only $33.33 \%$ of the housing operators are women. But the male operator is as high as $66.67 \%$. From the operating years, the number of new entrants to the industry is as high as $60 \%$. From this, we can also see that the current $\mathrm{B} \& \mathrm{~B}$ market is pretty hot that a large number of inexperienced gold miners enter the market. Only $20 \%$ of the properties in which they are engaged in B\&B are converted from their own houses. In the form of two landlords, as many as $70 \%$ of the landlords can be remade by signing a lease. In terms of the time limit, most housekeepers sign five-year rental contracts with landlords. The return on $\mathrm{B} \& \mathrm{~B}$ is not as optimistic as many people think, with nearly half of homeowners saying they earn less than 100,000 Yuan a year, or even just the same as the rent.

\section{APPLICATION OF FAMILY LIFE CYCLE}

Life is a process in which there are youth, middle age and old age. Every era has its own distinctive characteristics and unique way of life. But for B\&B, develop attractive products for different customer stages and lifestyles, to find a meeting point with the customer by providing service products that are required at different stages, which can ensure long-term stability of customers and funds as their operating basis. The author reviews the methods used by scholars at home and abroad for the division of family cycles, compares and summarizes (Table 4).and obtains a model suitable for the division of family cycles in this study. Divide the B\&B market into the following six parts for market segmentation(Table 5). 
Table 4

\begin{tabular}{|c|c|c|c|}
\hline & A & B & C \\
\hline 1 & Division of propose & Division basis & Division mode \\
\hline 2 & Wells\&Gubar(1996) & $\begin{array}{l}\text { Age of family owner, } \\
\text { marital status, spouse, } \\
\text { number and age of children }\end{array}$ & $\begin{array}{l}\text { 1.Single stage (young single and not living with family) } \\
\text { 2.Newly-married (childless) } \\
\text { 3.Full nest } 1 \text { (the youngest child is less than } 6 \text { years old) } \\
\text { 4.Full nest } 2 \text { (the youngest child is over } 6 \text { years old) } \\
\text { 5.Full nest } 3 \text { (the youngest child is married) } \\
\text { 6. Empty Nest } 1 \text { (children have left home because work) } \\
\text { 7. Empty Nest } 2 \text { (the child leaves home and retires) }\end{array}$ \\
\hline 3 & Boying Gan(2012) & Age of parents and children & $\begin{array}{l}\text { 1. Unmarried } \\
\text { 2. Young couples ( } 18-34 \text {, childless) } \\
\text { 3. Young parents ( } 18-34 \text {, youngest ehildren } 0-7 \text { ) } \\
\text { 4. Mature parents ( } 35-54 \text {, the youngest child age } 0-17) \\
\text { 5. Mature parents ( } 35-54 \text {, youngest children over } 18 \text { ) } \\
\text { 6. Mature couples ( } 35-54 \text {, childless) } \\
\text { 7. Older parents ( } 55+\text {, youngest } 0-17 \text { ) } \\
\text { 8. Older parents (over } 55 \text {, youngest children more than 18) } \\
\text { 9.Older ouples ( } 55+\text {, childless) }\end{array}$ \\
\hline 4 & Chunxiao Xu(2012) & $\begin{array}{l}\text { Marital status of couples and the stage } \\
\text { of their children's growth }\end{array}$ & $\begin{array}{l}\text { 1.1. Single (single / divorced / widowed; childless) } \\
\text { 2. Nesting period (husband and wife; childless) } \\
\text { 3. Full nest period 1: husband and wife / divore / widowed; child } \\
\text { infant / kindergarten) } \\
\text { 4. Full nest period 2: husband and wife / divoree / widowed; children } \\
\text { below primary school) } \\
\text { 5. Full nest period 3: husband and wife / divoree / widowed; children } \\
\text { in junior high school) } \\
\text { 6. Full nest 4: husband and wife / divoree / widowed; children go to } \\
\text { college) } \\
\text { 7. Empty nest period (husband and wife; children have lived } \\
\text { independently) }\end{array}$ \\
\hline
\end{tabular}

Table 5

\begin{tabular}{|l|l|l|l|}
\hline Stages of the family life cycle & Age & Marital status \\
\hline Student stage & $18-25$ & single & Child growth stage \\
\hline Single stage & $25-35$ & single & married \\
\hline Honeymoon stage & $25-35$ & married & At least one child aged 1-6 \\
\hline Former parent stage & $25-35$ & married & At the age of study \\
\hline Middle parent stage & $36-55$ & married/ divorced/ widowed & Children have lived independently \\
\hline Post-parent stage & $36-55$ & \\
\hline
\end{tabular}

In this study, the family life cycle is divided into six stages based on the marital status and the growth stage of the children as the basis of family characteristics. (excluding life stages over the age of 55). There are: 1.Student stage; 2. Single stage; 3.Honeymoon stage; 4.Former parent age; 5.Middle parent stage; 6.Post parent stage( Table 5). 


\section{Student stage: the extension of the study period in China}

Chinese students go to university at the age of 18 and graduate from university at the age of 23. According to statistics from the Ministry of Education, the number of applicants for graduate school has grown rapidly in recent years, reaching 2.38 million in 2018 (Table 6), an increase of 370000 over 2017 and an increase of 18.4\%. Therefore, the average age of Chinese students is 18-25 years. A survey conducted by the Social Survey Center of the China Youth Daily Association on postgraduate studies shows that there are two main reasons why a large number of students continue to study: 1. Ease employment pressure, as far as the current employment situation is concerned, students are under great pressure of employment, the recruitment threshold of the unit is gradually raised, and the requirements for academic qualifications are strict. Therefore, the large number of students choose to avoid the severe employment situation by taking the entrance examination to graduate school, and at the same time, they can improve their academic qualifications. 2. To change major, for the university major is mostly by the influence of parents, can change through the examination for more suitable for their own major, but also for those students who failed in the college entrance examination to re-enter the opportunity to enter the famous school.

Table 6

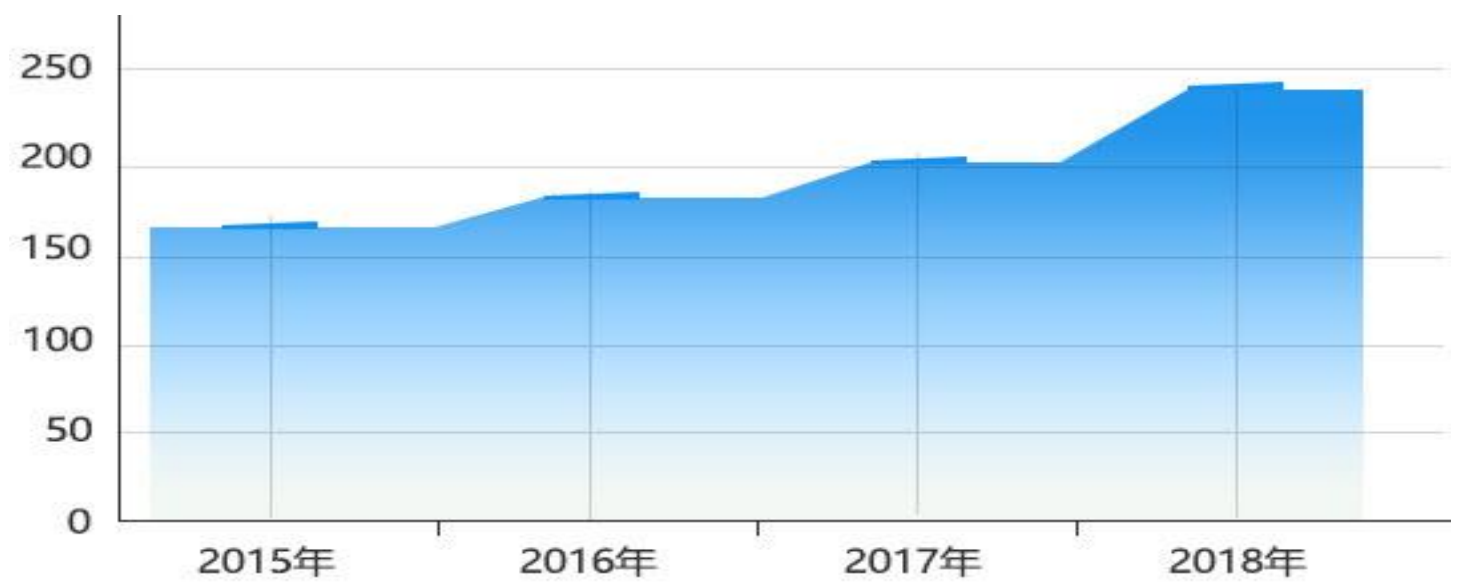

图1、近4年（2015-2018）硕士研究生报名人数（单位：万人) 数据来源：教育部

As a result, a large proportion of the 18-25 age group still belongs to the student stage, which is characterized by a limited economy, some of them are already in work but still require the help from their parents. According to Pi \& Jing (2016) has a survey of college students showed that they pay more attention to the price, safety, personality etc. The prominent family hotel as their destination for the journey. At this stage, people have a strong willingness to try different accommodation experience, highly dependent on the network, the characteristics of travel is group travel. According to the 2016 consumer group analysis released by Kimiao Short-Rent, 38 percent of Chinese B\&B bookings from the age of 18-25 
years, mainly among the younger generation. Of these users, $42 \%$ have the flexibility to spend about 600 yuan a month. Therefore, the B\&B market for university students should collective accommodation needs of two, three, four or even more than a dozen people. Such as, whole rent and single rent will increase the attention of these people.

\section{2、 Single stage}

According to Tuniu's <single Tourism Consumption Analysis 2017>, Chinese single population is as high as 200 million, which is equal to the combined population of Russia and Britain. Tourism is one of the most popular leisure and consumption methods for single men and women. In addition, basic on the latest Mintel (2017) report < Marketing for single consumers China 2017>, 61\% of single consumers are most interested in movies / TV, followed by travel $56 \%$ and exercise and fitness $48 \%$.Tuniu's monitoring data show that the main force of single tourism is mainly between the ages of 26 and 35, and the monthly income of this group is mainly concentrated in the $6 \mathrm{~K}-10 \mathrm{~K}$, accounting for 42.84 percent, and the consumption habits are between moderate consumption and advanced consumption, more enthusiastic about socializing. What can not be ignored in the single group is the tourist consumption ability of single women. A market survey for British hotels found that 40 percent of customers lost their services to women (Frank , 2010). This group of customers has a higher income and a low burden on their families, most of the well-educated professional women pay more attention to details, atmosphere and sense of security, most will choose to go out together on holidays, relax body and mind as the main purpose and rely on a big portal's comment on the websites. Therefore, in the B\&B market for single men and women need to consider the price moderate, more social needs. It is the key to create a safe and healthy living environment for single women market.

\section{3、Honeymoon stage}

The married young couple, between 25 - 35 years of age and childless, disposable income for leisure is higher. Young couples at this stage pursue a sweet world of two, therefore tend to pay more attention to romantic tourist destinations, and choose resorts with high standards of reception facilities, the tourism consumption ability is strong. Willing to try a new type of accommodation experience, in order to ease the pressure of work, promote mutual affection, more attention will be paid to the "privacy" of residential accommodation. 


\section{The former parents' stage}

The married young couple, Between 25 -35 years of age, with children ranging from 0 to 6 years of age. This phase is the peak period for household goods purchases, which have less disposable income for tourism. Combined with a large number of travel items for children, they focus on short trips, cultivating children's perception of the outside world is a key factor in traveling. According to the investigation, the market for online parent-child travel is estimated to reach 20.79 billion Yuan in 2016, and parents' needs for children aged 2 to 6 tend to be based on their children's perception of nature and rural farming experience almost 2 to 3 days, the experience includes manual DIY, parent-child interaction and natural sightseeing. This group of customers is more concerned about accessibility, the safety of accommodation and child participation which can attract target customers by improving their physical fitness, hands-on ability and enjoying with children's time. For example, to develop more characteristic extended parent-child activities in the B\&B agglomeration area, and to develop their own competitive advantage by offering accommodation discount to different families.

\section{The middle parents' stage}

The married / divorced / widowed, the age period is between 36 and 55, the children are in the middle school or high school stage, and they face the pressure of going to school and the pressure of exam. Travel times are chosen for weekends or vacations, and tend to be educational destinations that enhance the relationship between parents and children. In view of this customer group, the rural folk culture can be taken as the core. Development of "small and refined" and other efficient experience forms of parent-child's B\&B. Such as can develop a student market dominated by study tours to create unlimited happiness for families in a limited time.

\section{Post-parental stage:}

The married / divorced / widowed, the children are independent and the family is empty nest situation. Couples are also nearing retirement, have more independent time, travel disposable income increases than before. These groups have a unique yearning for the quiet and comfortable life in the countryside or have had memories of living in the countryside, the current state of life is relatively simple, and the circle of friends gradually shrinks (Zhang\&Jin,2016). Therefore, the new trend of "B\&B+ Pension" has been proposed. In the face of this kind of such a situation, the scattered operation should be avoided and move the concept of community in the city to the rural areas, form a cluster community for the pension community. At the same time, supporting service systems and facilities and equipment systems should be taken into account. For example: college for the elderly, activity room, canteen, etc (Chen,2017). 


\section{CONCLUSION}

In this article, the author takes the method of collecting information to study the B\&B market in the domestic. Facing the reshuffle period of the B\&B industry, the goal is the sustainable management of the $\mathrm{B} \& \mathrm{~B}$ industry. Through the summary of previous scholars, using the life cycle of the family to subdivide the domestic B\&B market, there are six life cycles, which includes student stage; Single stage; Honeymoon stage; The former parents' stage; The middle parents' stage; Post-parental stage. According to the characteristics of each stage, the $\mathrm{B} \& \mathrm{~B}$ operators can better judge their own strength and find the target customer groups. Thus the targeted sales of $\mathrm{B} \& \mathrm{~B}$ products to achieve the purpose of sustainable management.

\section{REFERENCE}

1.PI Chang-ling, ZHENG Xiang-min(2016), Journal of Fujian Agriculture and Forestry University (Philosophy and Social Sciences), Study on the bed and breakfast choice preference of undergraduate tourists, No 2, page 71-78.

2.Chen xiaoqian (2017), Research on the Innovation of New Media Application based on the connection of Health and Endowment Tourism and Residential Resources, Journal of Zhejiang Institute of Communication.

3.Zhang wen, Jing xiuling (2017). " Feasibility analysis of the development of residential pension institutions in Hangzhou. The economy, 10(2016):00057-00057.

4. Zeng zhang\&Jiang yong,2018. Journalof ChaohuCollege , No.2.,Vol.20.2018 GeneralSerialNo.149.

5.WILLIAM D. WELLS and GEORGE GUBA(1966),R,Life Cycle Concept in Marketing Research, Journal of Marketing Research, Vol. Ill (November, 355-63)

6.Kotle Philip, Bowen T. John, Makens C. James (2014). Marketing for Hospitality and Tourism. Person Education, Inc. American.

7.Camacho E. Frank (2010). "Listening to Customers: The Market Research, Function at Marriott Corporation” Marketing Research (March, 2010)

8.Lazer William and Layton A.Roger (2000) Contemporary Hospitality Marketing, $2^{\text {nd }}$ ed, Education institute, American.

9. Cornell Hotel and Restaurant Administration Quarterly (May, 2008)

10. Couch, C. (2010, February 11). B\&B investors demand information from government. Financial Adviser, p. N/a 
11. Chen, L., Lin, S. \& Kuo, C. (2013), "Rural tourism: Marketing strategies for the bed and breakfast industry in Taiwan", International Journal of Hospitality Management, vol. 32, pp. 278-286. 